\title{
FINITE ELEMENT MODEL UPDATING METHODS FOR STRUCTURAL APPLICATION
}

\author{
Suzana Ereiz, Ivan Duvnjak \& Javier Fernando Jimenez-Alonso
}
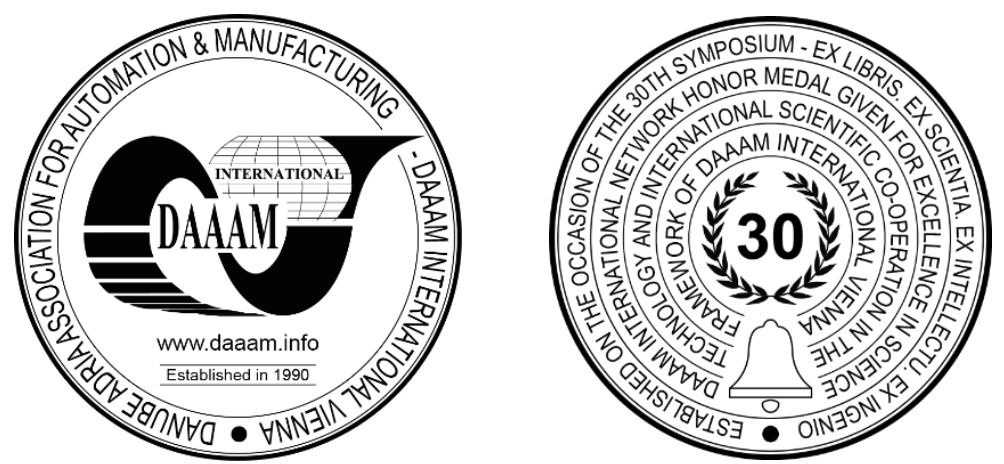

This Publication has to be referred as: Ereiz, S[uzana]; Duvnjak, I[van] \& Jimenez-Alonso, J[avier] F[ernando] (2021). Finite Element Model Updating Methods for Structural Application, Proceedings of the 32nd DAAAM International Symposium, pp.0712-0718, B. Katalinic (Ed.), Published by DAAAM International, ISBN 978-3-902734-33-4, ISSN 1726-9679, Vienna, Austria

DOI: $10.2507 / 32$ nd.daaam.proceedings.099

\begin{abstract}
Structural finite element models are a modern tool for continuous monitoring of structures, damage detection, prediction of service life and determination of optimal strategy for maintenance. It is well known that we get uncertain numerical models due to the input parameters such as stiffness, mass, and boundary conditions. To solve this problem, finite element model updating methods are used in combination with the results of structural dynamic tests or structural health monitoring data. In this paper, a brief overview of the procedure for updating finite element models using experimentally determined structural dynamic parameters - natural frequencies and natural modes - is given. Some of the most commonly used methods are listed and their advantages and disadvantages are highlighted.
\end{abstract}

Keywords: Finite element model updating; Structural health monitoring; Dynamic analysis of structures; experimental investigation

\section{Introduction}

Finite element model updating (FEMU) emerged in the 1990s as a topic of the great importance for the design [1], [2], [3], construction [4], [5], [6] and maintenance of mechanical systems [7], [8], [9] and structures [10] [11] [12] [13]. As for civil engineering structures, it refers to the updating of its models to assume its dynamics behaviour more precise and accurate. To minimize the differences and maximize the correlation between the numerical model and the real structure, the model updating (MU) of the civil engineering structure is most often performed by applying the structural dynamic test results.

In addition to dynamic, the static test results [14], [15], [16], [17] or its combination with dynamic test results is also apply [18], [19], [20], [21]. The conducting of FEMU is mainly focused on the determination of most relevant structural parameter values such as geometry, material properties, and boundary conditions. Those parameters minimize the differences between the structural behaviours predicted by the numerical model from the actual behavior of the structure. The reasons why there are differences between the predicted behavior of a numerical model of the structure and its actual behavior include model structure errors, model order errors, model parameter errors, and errors in measurements [22]. 


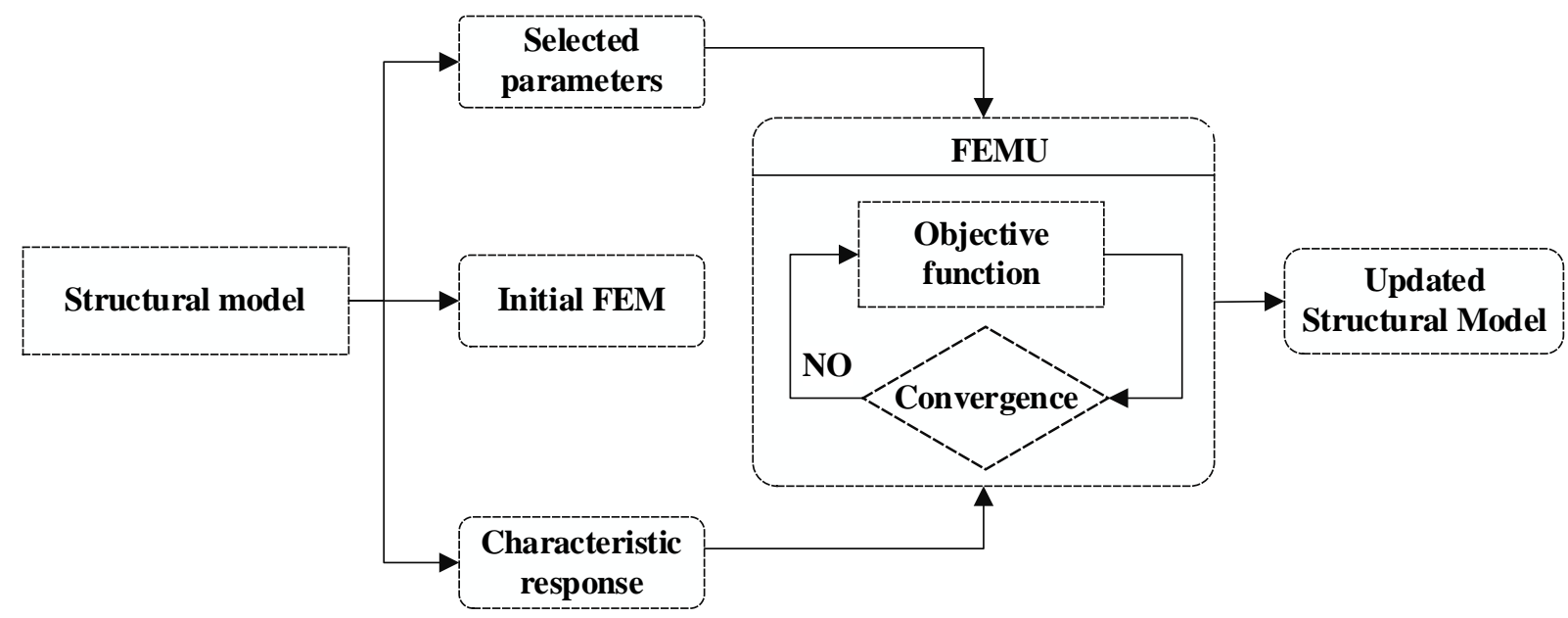

Fig. 1. Flowchart of FEMU procedure

Model structure errors arise from incorrect assumptions of the mechanical properties and physical behaviour of structures [23], [24]. Second one, model order errors, most often arise from the difficulty in the modelling of the nonlinearity [14]. Model parameter errors arise from the incorrect assumptions of model parameters- material and geometrical properties. Measurement errors occur in the measurements, where due to the influence of various environmental effects and other different factors an error may occur. Many of investigation is mainly focused on the finite element model updating using structural dynamic parameters - natural frequency, mode shapes and damping ratio. The advantages of using these parameters are that they are easy to apply for damage detection. Also, they are most appropriate when there is a large error in the numerical modelling, and they are directly related to the topology of the structure. In this type of data, most of the structural parameters that best describe the global behavior are include [25]. On the other hand, the determination of the structural dynamic properties for identification is computationally intensive and prone to additional noise. Moreover, it is not able to extract the modes of the frequency bandwidth and is only suitable for highly damped and linear structures [25].

The FEMU method can generally be classified as the automated and manual methods [26], and iterative(non-direct) and non-iterative (direct) methods [27]. The main difference between the manual and automated method lies in the number of selected updating parameters and in the way the model updating is performed - using trial and error methods (manual FEMU) or automated process. There is also a difference in the obtained results, where in manual methods the difference between predicted and actual behavior of structure is less than 5\% while in automated methods it is less than $1 \%$ [28]. The division of MU methods into iterative and non-iterative methods is somewhat more concrete. As their name say the differences between them is in the way the model updating is implemented, using iterative process or not. The iterative methods are further divided into deterministic methods and Bayesian method. Based on the targeted responses used to update the numerical model, deterministic methods can be further divided into two groups: (1) methods that use eigenvalues and eigenvectors (eigenfrequencies, mode shapes, damping coefficient) and (2) methods that use frequency response data. The Bayesian method treats numerical models as statistical problems and aims to develop a set of numerical models that will represent the actual behavior of the structure [29]. They are aimed at quantifying the uncertainties of the selected updating parameters [30]. The aim of this paper is to present the procedure of model updating by selecting the parameters for numerical model updating, defining the difference function between the predicted and the actual behavior of the structure, and by presenting the most commonly used methods for minimizing the difference. In this way, an review as well as the capacity of the approaches proposed so far is given, on the basis of which some new approaches can be proposed. In the following (second section) the procedure for selecting the parameters of the numerical model is described, through which iteration the numerical model is improved to match the real behavior of the structure. The third section describes how to define the difference between the real and the predicted behavior of the structure, depending on whether the approach to model updating is deterministic or stochastic. Section 4 gives a review of the methods most commonly used in model updating and their advantages and disadvantages.

\section{Selection of the updating parameters}

The success of the finite element model update implementation depends on the selection of the updating parameters. It is very important to properly define the model parameterization and estimate the unknown parameters from illconditioned equations. In addition to parameterization, the uniqueness of the updating parameters, computational efficiency, ill-conditioned equations, and the use of incomplete data is also important. The selected parameters of the numerical model that are being updated should be able to explain the uncertainties or inaccuracies of the model, provided that the output data are sensitive to the input parameters of the model [31]. There are several methods that are used for selection of updating parameters. 


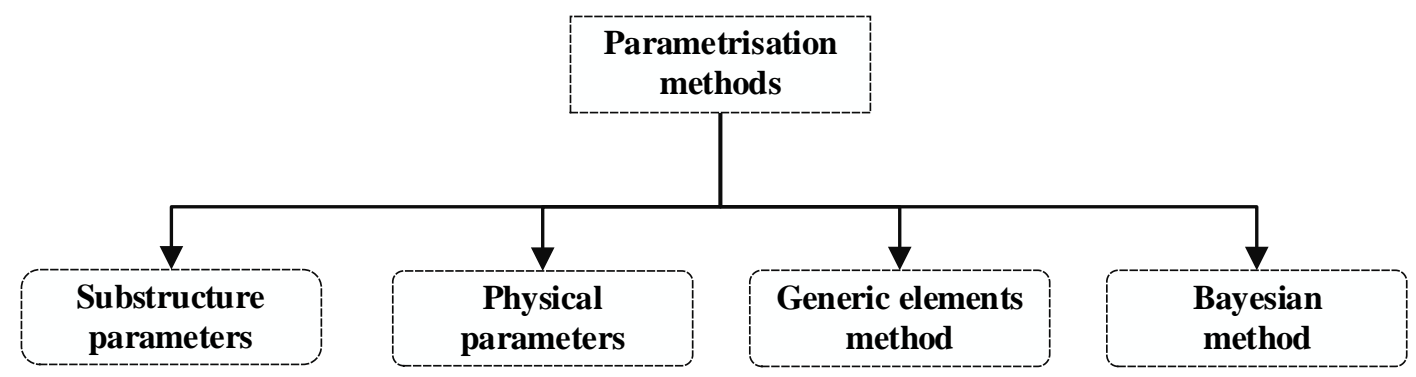

Fig. 2. Parametrisation methods for FEMU

One of them is to define the scalar multipliers associated with the mass, stiffness and damping matrices [32]. Second parametrization method employs the direct material and geometrical properties of structures [33]. Third one, generic method [34] by adjusting the eigenvectors and eigenvalues of individual elements or sub-structure update the stiffness and mass matrices. Regardless of the selected parameterization method, the set of selected updating parameters should be as small as possible to eliminate unnecessary parameters and reduce computational cost. Their number is also limited by the amount of information available from measurements in a limited frequency range.

\section{Definition of the objective and probability density function}

Formulation of the objective function for the FEMU problem must take into account the residuals that are sensitive to the selected updating parameters [35]. Objective function in problem of FEMU is the residuals which defined the differences between structural behaviour predicted by numerical model and its actual behaviour. Usually, it is most defined by considering two types of residuals. The first one is associated with the natural frequencies while the second is associated with the corresponding mode shapes. Also, the objective function can be defined by considering the residual associated with the damping ratio [36]. The influence of those residuals on the objective function can be evaluated via two approaches: the single objective function (1) and multi objective function (2) approach.

$$
\begin{aligned}
& F(x)=\sum_{i=1}^{N F} w_{i} F_{i}(x) \\
& \left(F_{i}(x)\right)=\left(F_{1}(x), F_{2}(x), \ldots, F_{N F}(x)\right)
\end{aligned}
$$

Single objective function (1) approach is characterized by only one objective function. This function is defined in terms of the sum of weighted residuals. The values of weighted residual are usually obtained using the trial-and-error method or a probabilistic method in terms of the standard deviation of the experimental data. On the other hand, in the multi objective function approach (2) each component of the objective function is defined in terms of unweighted residuals. Several non-dominated solutions are obtained which form a Pareto front. As the solutions is non-dominate a decision-making problem must be solved. The best solution is selected from the Pareto front by determining the knee point. Knee point is a solution from the Pareto front that has a maximum marginal utility. It represent the locally the best trade - off solutions among the considered objective values [36]. In the stochastic approach, a numerical model is updated to the multiple sets of predicted results using multivariate multiple regression. In this way, a parameter sensitivity matrix is created that accounts for the entire population of randomized values for all parameters together. Differences between the experimentally and numerically obtained data are minimized using a gradient and regression approach to obtain improved estimates of the mean value of the randomized parameters at each step [37].

In Bayesian method [38] instead an objective function probability density function (PDF) is defined in terms of the posterior $\operatorname{PDF}-\mathrm{P}\left(\theta \mid \widetilde{\mathrm{M}}, \widetilde{\mathrm{M}}_{\mathrm{m}}\right)$, likelihood function-P$\left(\widetilde{\mathrm{M}} \mid \theta, \widetilde{\mathrm{M}}_{\mathrm{m}}\right)$, normalisation function-P $\left(\widetilde{\mathrm{M}} \mid \widetilde{\mathrm{M}}_{\mathrm{m}}\right)$ as follows (3)

$$
P\left(\theta \mid \widetilde{M}, \widetilde{M}_{m}\right)=\frac{P\left(\widetilde{M} \mid \theta, \widetilde{M}_{m}\right) P\left(\theta \mid \widetilde{M}_{m}\right)}{P\left(\widetilde{M} \mid \widetilde{M}_{m}\right)}
$$

\section{Finite element model updating methods}

\subsection{Matrix update methods}

The matrix update method is mainly based on updating the structural mass, stiffness or damping matrices. They are implemented to minimize the differences between the analytical and measured matrices. The main concept is based on changing the global stiffness, mass or damping matrices to an improved numerical model that accurately reproduces the experimental results [39]. Their application directly minimizes the differences between experimentally and numerically obtained structural dynamic parameters. These methods are computationally expensive and it is difficult to find a global minimum through the optimization techniques since there are several stationary points [22]. Besides, it is difficult to achieve a solution with the physical meaning. 


\subsection{Sensitivity based methods}

Sensitivity-based methods are the most successful approach with many applications to the MU problems. In these methods, the experimentally obtained structural dynamics parameters - natural frequencies and mode shapes are adopted for updating the initial numerical model. These methods allow a wide choice of the parameters for model updating and measured outputs to be weighted. With the respect to parameters, determination of the sensitivity of the measurements is computationally intensive and the approximation of the sensitivity may only be obtained. The sensitivity is most often the non-linear function of the updating parameters, an iterative procedure is necessary [40]. This iterative procedure is associated with the convergence problem to solve for the selected parameters [41]. Sensitivity based method has some limitations related to request of existence of a sensitivity matrix with the respect to all updating parameters. This led to the expensive computation. On the other hand this method may not be applicable for structure which contain a considerable amount of damage [22].

\subsection{Dynamic perturbation and regularization method}

As the sensitivity based method works well when the differences between the predicted and actual structural behaviour is relatively small, in the case where such difference is sufficiently large, the linear or first order approximations may be inappropriate [41]. An exact relationship between the perturbation of structural parameters and the perturbation of the associated dynamic parameters is used for the FEMU. This method directly adopts the measure incomplete structural dynamic parameters and in the FEMU process it doesn't require mode shape expansion or reduction [42]. This method needs much less computational effort to estimate updating parameters. It provides optimised solutions for MU in the least squares sense without requiring optimisation techniques [43]. Also, this method offers reliable estimates of structural updating parameters, even in the cases where relatively large modifications in structural parameters and/or in modal properties exist between the finite element model and the tested structure [44].

\subsection{Iterative optimization procedure}

Iterative optimization methods transform the FEMU into the optimization problem. On this way the objective function is defined as (here there is a typo) the relative differences, i.e., residuals, between the behaviour of structure predicted by numerical model and its actual behaviour. There are two different ways in which these residuals can be defined. The first one is as single objective optimization problem, while the second one is the multi-objective optimization problem [45]. As the name says, the first optimization problem- single objective is characterized with only one objective function define in terms of the sum of the weighted residuals. The final values of the weighted residuals are usually derived from a trialand-error process.

\subsection{Bayesian method and Fuzzy methods}

The Bayesian FEMU method approaches on the development of the numerical model as a statistical problem focusing on the estimating the probabilistic density function of the numerical model physical parameters. This method uses Bayesian probability theory [46] for estimating the posterior probability density function of the physical parameters of the model. Density function is estimated in terms of the likelihood and prior probability density functions [29]. The likelihood function measures the discrepancies between the numerical and experimental structural dynamic properties. The prior probability density function reflects a previous assumption about the statistical behavior of the physical parameters of the FE model. Including its advantages, this method has a disadvantage related to a complex numerical model, which is often time consuming and computationally limited, limiting its applicability to the large real structures.

\subsection{Computational intelligence algorithms}

Finite element model updating is an optimization method in which the design variables are the uncertain parameters of the model [47]. The objective is to minimize the distance between the structural behavior predicted by numerical model and its actual behavior obtained by conducting the experimental investigation. To solve the optimization problem of FEMU the computational intelligence algorithms are used (Figure 3).

This techniques mostly include the Nelder mead simplex method [48], sequential programming technique [49], genetic algorithm [50], particle swarm optimization [51], simulated annealing [44], response surface method [52], hybrid optimization [53] and multi objective optimization [54] and all the other algorithms 


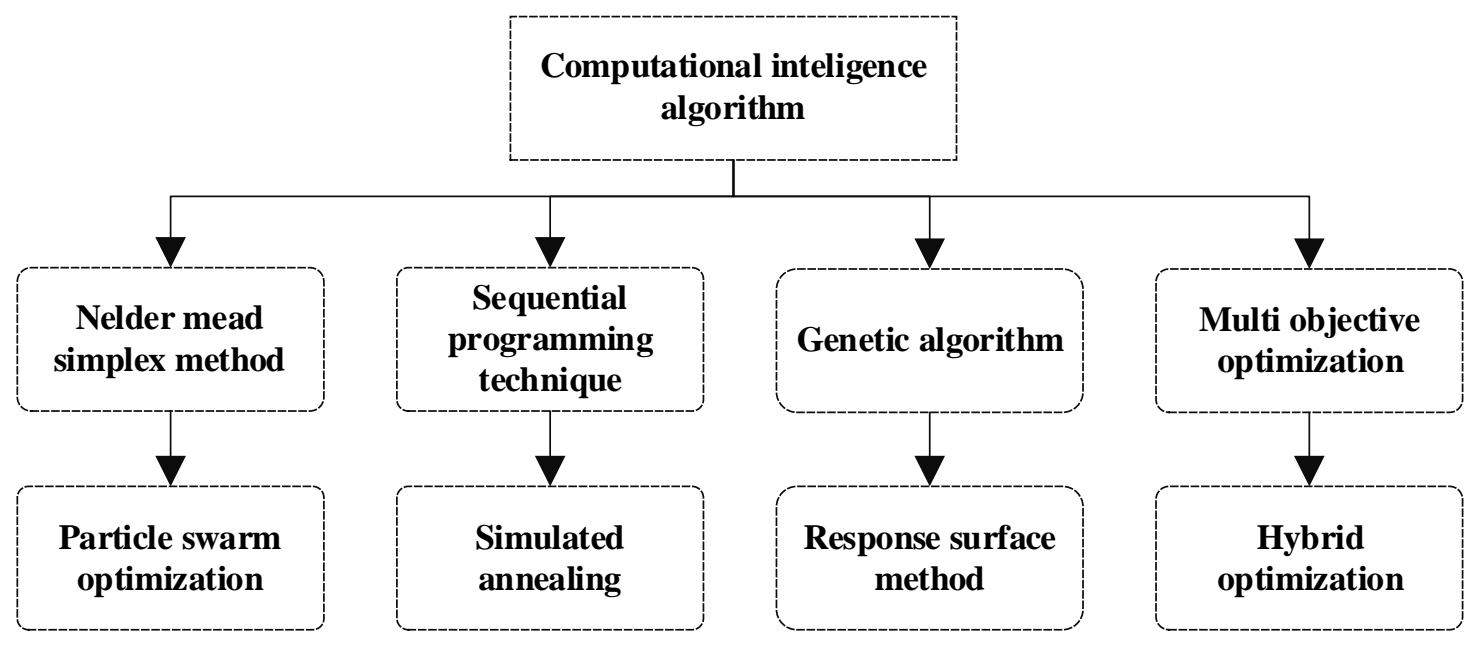

Fig. 3. Computation intelligence algorithm for FEMU

\section{Conclusion}

With the ever-advancing development of computer software and structural health monitoring techniques, everincreasing demands are being placed on the numerical modelling of structures. This has created a need for the development of methods that combine computer software and SHM techniques into numerical models to describe real structure as accurately and precisely as possible. The numerical models obtained can be used for various purposes, from monitoring the construction phases, to the maintenance of the structure and its restoration, to important related decisions. This paper gives a brief overview of the process of implementing model updating and the most used methods for this purpose. Moreover, a way to select the updating parameters and to define the differences between the behavior of the structure predicted by the numerical model and the actual one is given. Based on the review performed, it can be concluded that the selection of the model updating method depends on the test settings of the structure and the numerical model, on the complexity of the structure and on the way of defining the difference between the behavior of the structure predicted by the numerical model and its actual behavior. It turned out to be very important to correctly define the function and the appropriate algorithm that ensures its solutions. Due to the complexity of numerical models for certain types of structures, updating their model is a very time-consuming and expensive process and requires a large amount of computation. Therefore, for further research, it is proposed to develop an algorithm that reduces the time and computational cost required to improve the numerical model without compromising the accuracy of the updated solution (optimal value of the selected parameters).

\section{Acknowledgments}

This research was funded by the European Union through the European Regional Development Fund's Competitiveness and Cohesion Operational Program, grant number KK.01.1.1.04.0041, project "Autonomous System for Assessment and Prediction of infrastructure integrity (ASAP)."

\section{References}

[1] Zapico, J.L., González, M.P., Friswell, M.I., Taylor, C.A., Crewe, A.J. (2003). Finite element model updating of a small scale bridge, Journal of Sound and Vibration, 268, (993-1012), https://doi.org/10.1016/S0022460X(03)00409-7.

[2] Modak, S. V., Kundra, T.K., Nakra, B.C. (2002) Use of an updated finite element model for dynamic design, Mechanical Systems and Signal Processing, 16, (303-322), https://doi.org/10.1006/mssp.2001.1431.

[3] Structures, T., Technical, C., Republic, C., Arora, V., Ilcik, J., Republic, C. (2014). Updating finite element model of façade scaffolds anchor considering experimental data, (1-11),

[4] Li, Z., Feng, D., Feng, M.Q., Xu, X. (2017). System identification of the suspension tower of Runyang Bridge based on ambient vibration tests, Smart Structures and Systems, 19, (523-538), https://doi.org/10.12989/sss.2017.19.5.523.

[5] Zong, Z., Lin, X., Niu, J. (2015). Finite element model validation of bridge based on structural health monitoringPart I: Response surface-based finite element model updating, Journal of Traffic and Transportation Engineering (English Edition), 2, (258-278), https://doi.org/10.1016/j.jtte.2015.06.001.

[6] Sequera Gutierrez, D., Solano Rodríguez, L.F., Muñoz Díaz, E.E., Alvarado Vargas, Y.A., Villalba Morales, J.D., Gasch Molina, I. (2020). Updating the finite element model of a Colombian Bridge with Ansys, Dyna, 87, (209218), https://doi.org/10.15446/dyna.v87n212.79785. 
[7] Wang, W., Mottershead, J.E., Ihle, A., Siebert, T., Reinhard Schubach, H. (2011). Finite element model updating from full-field vibration measurement using digital image correlation, Journal of Sound and Vibration, 330, (15991620), https://doi.org/10.1016/j.jsv.2010.10.036.

[8] Butkewitsch, S., Steffen, V. (2002). Shape optimization, model updating and empirical modeling applied to the design synthesis of a heavy truck side guard, International Journal of Solids and Structures, 39, (4747-4771), https://doi.org/10.1016/S0020-7683(02)00372-4.

[9] Kwon, K.S., Lin, R.M. (2004). Frequency selection method for FRF-based model updating, Journal of Sound and Vibration, 278, (285-306), https://doi.org/10.1016/j.jsv.2003.10.003.

[10] Schommer, S., Nguyen, V.H., Maas, S., Zürbes, A. (2017). Model updating for structural health monitoring using static and dynamic measurements, Procedia Engineering, 199, (2146-2153), https://doi.org/10.1016/j.proeng.2017.09.156.

[11] Altunişik, A.C., Karahasan, O.Ş., Genç, A.F., Okur, F.Y., Günaydin, M., Kalkan, E., Adanur, S. (2018). Modal parameter identification of RC frame under undamaged, damaged, repaired and strengthened conditions, Measurement: Journal of the International Measurement Confederation, 124, (260-276), https://doi.org/10.1016/j.measurement.2018.04.037.

[12] Nguyen, A., Kodikara, K.T.L., Chan, T.H.T., Thambiratnam, D.P. (2019). Deterioration assessment of buildings using an improved hybrid model updating approach and long-term health monitoring data, Structural Health Monitoring, 18, (5-19), https://doi.org/10.1177/1475921718799984.

[13] Bayraktar, A., Sevim, B., Can Altunişik, A. (2011). Finite element model updating effects on nonlinear seismic response of arch dam-reservoir-foundation systems, Finite Elements in Analysis and Design, 47, (85-97), https://doi.org/10.1016/j.finel.2010.09.005.

[14] Sun, L., Li, Y., Zhu, W., Zhang, W. (2020). Structural response reconstruction in physical coordinate from deficient measurements, Engineering Structures, 212, (110484), https://doi.org/10.1016/j.engstruct.2020.110484.

[15] Kim, S., Young, K., Lee, J. (2016). Bridge Finite Model Updating Approach By Static Load Input / Deflection Output Measurements : Field Experiment, in: The 2016 Structures Congress (Structures 16), Jeju Island, Korea,

[16] Schlune, H., Plos, M., Gylltoft, K. (2009). Improved bridge evaluation through finite element model updating using static and dynamic measurements, Engineering Structures, 31, (1477-1485), https://doi.org/10.1016/j.engstruct.2009.02.011.

[17] Mylonas, C., Abdallah, I., Chatzi, E.N. (2010). Conference Proceedings of the Society for Experimental Mechanics Series, in: T. Proulx (Ed.), Bayesian Finite Element Model Updating Using Static and Dynamic Data, Springer, Bethel, USA, : pp. 189-196.

[18] Ismail, Z., Kuan, K.K., Yee, K.S., Chao, O.Z. (2014). Examining the trend in loss of flexural stiffness of simply supported RC beams with various crack severity using model updating, Measurement: Journal of the International Measurement Confederation, 50, (43-49), https://doi.org/10.1016/j.measurement.2013.12.036.

[19] Oh, B.K., Kim, D., Park, H.S. (2017). Modal Response-Based Visual System Identification and Model Updating Methods for Building Structures, Computer-Aided Civil and Infrastructure Engineering, 32, (34-56), https://doi.org/10.1111/mice.12229.

[20] Zhou, L., Wang, L., Chen, L., Ou, J. (2016). Structural finite element model updating by using response surfaces and radial basis functions, Advances in Structural Engineering, 19, (1446-1462), https://doi.org/10.1177/1369433216643876.

[21] Seon Park, H., Kim, J.H., Oh, B.K. (2019). Model updating method for damage detection of building structures under ambient excitation using modal participation ratio, Measurement: Journal of the International Measurement Confederation, 133, (251-261), https://doi.org/10.1016/j.measurement.2018.10.023.

[22] Marwala, T. (2010). Finite-element model Updating Using Computational Intelligence Techniques, 1st ed., Springer-Verlag London, London, England, https://doi.org/10.1007/978-1-84996-323-7.

[23] Sun, L., Li, Y., Zhang, W. (2020). Experimental Study on Continuous Bridge-Deflection Estimation through Inclination and Strain, Journal of Bridge Engineering, 25, (04020020), https://doi.org/10.1061/(asce)be.19435592.0001543.

[24] Farshadi, M., Esfandiari, A., Vahedi, M. (2017). Structural model updating using incomplete transfer function and modal data, Structural Control and Health Monitoring, 24, (1-13), https://doi.org/10.1002/stc.1932.

[25] Ewins, D.J. (2000). Modal Testing: Theory, Practice and Application, Second Edi, Research Studies Press Ltd, Hertfordshire,

[26] Altunişik, A.C., Karahasan, O.Ş., Okur, F.Y., Kalkan, E., Ozgan, K. (2019). Finite element model updating and dynamic analysis of a restored historical timber mosque based on ambient vibration tests, Journal of Testing and Evaluation, 47, https://doi.org/10.1520/JTE20180122.

[27] Marwala, T. (2010). Finite-element-model updating using computional intelligence techniques: Applications to structural dynamics, 1st ed., Springer-Verlag London, London, England, https://doi.org/10.1007/978-1-84996-3237.

[28] Altunişik, A.C., Kalkan, E., Okur, F.Y., Karahasan, O.Ş., Ozgan, K. (2020). Finite-Element Model Updating and Dynamic Responses of Reconstructed Historical Timber Bridges using Ambient Vibration Test Results, Journal of Performance of Constructed Facilities, 34, https://doi.org/10.1061/(ASCE)CF.1943-5509.0001344. 
[29] Goller, B., Schuëller, G.I. (2011). Investigation of model uncertainties in Bayesian structural model updating, Journal of Sound and Vibration, 330, (6122-6136), https://doi.org/10.1016/j.jsv.2011.07.036.

[30] Simoen, E., De Roeck, G., Lombaert, G. (2015). Dealing with uncertainty in model updating for damage assessment: A review, Mechanical Systems and Signal Processing, 56, (123-149), https://doi.org/10.1016/j.ymssp.2014.11.001.

[31] Naranjo-Pérez, J., Jiménez-Alonso, J.F., Pavic, A., Sáez, A. (2021). Finite-element-model updating of civil engineering structures using a hybrid UKF-HS algorithm, Structure and Infrastructure Engineering, 17, (620-637), https://doi.org/10.1080/15732479.2020.1760317.

[32] Stubbs, N., Kim, J.T. (1996). Damage localization in structures without baseline modal parameters, AIAA Journal, 34, (1644-1649), https://doi.org/10.2514/3.13284.

[33] Friswell, M.I., Mottershead, J.E., Ahmadian, H. (2001). Finite-element model updating using experimental test data: Parametrization and regularization, Philosophical Transactions of the Royal Society A: Mathematical, Physical and Engineering Sciences, 359, (169-186), https://doi.org/10.1098/rsta.2000.0719.

[34] Ahmadian, H., Gladwell, G.M.L., Ismail, F. (1997). Parameter selection strategies in finite element model updating, Journal of Vibration and Acoustics, Transactions of the ASME, 119, (37-45), https://doi.org/10.1115/1.2889685.

[35] Alkayem, N.F., Cao, M., Zhang, Y., Bayat, M., Su, Z. (2018). Structural damage detection using finite element model updating with evolutionary algorithms: a survey, Neural Computing and Applications, 30, (389-411), https://doi.org/10.1007/s00521-017-3284-1.

[36] Grafe, H. (1998). Model Updating of Large Structural Dynamics Models Using Measured Response Functions, University of London https://doi.org/10.1002/eqe.2925.

[37] Mares, C., Mottershead, J.E., Friswell, M.I. (2006). Stochastic model updating: Part 1-theory and simulated example, Mechanical Systems and Signal Processing, 20, (1674-1695), https://doi.org/10.1016/j.ymssp.2005.06.006.

[38] Marwala, T., Boulkaibet, I., Adhikari, S. (2017). Probabilistic Finite Element Model Updating using Bayesian Statistics. Application to aeronautical and mechanical engineering, First, John Wiley \& Sons, Ltd Registered, Chichester, UK, .

[39] Girardi, M., Padovani, C., Pellegrini, D., Porcelli, M., Robol, L. (2020). Finite element model updating for structural applications, Journal of Computational and Applied Mathematics, 370, (112675), https://doi.org/10.1016/j.cam.2019.112675.

[40] Jung, D.S., Kim, C.Y. (2013). Finite element model updating on small-scale bridge model using the hybrid genetic algorithm, Structure and Infrastructure Engineering, 9, (481-495), https://doi.org/10.1080/15732479.2011.564635.

[41] Chen, H.-P. (2018). Structural health monitoring of civil engineering structures, John Wiley and Sons Inc., https://doi.org/10.1002/pse.2260010313.

[42] Zhou, X.Q., Xia, Y., Weng, S. (2015). L1 regularization approach to structural damage detection using frequency data, Structural Health Monitoring, 14, (571-582), https://doi.org/10.1177/1475921715604386.

[43] Hua, X.G., Ni, Y.Q., Ko, J.M. (2009). Adaptive regularization parameter optimization in output-error-based finite element model updating, Mechanical Systems and Signal Processing, 23, (563-579), https://doi.org/10.1016/j.ymssp.2008.05.002.

[44] Chen, H.P., Tee, K.F. (2014). Structural finite element model updating using incomplete ambient vibration modal data, Science China Technological Sciences, 57, (1677-1688), https://doi.org/10.1007/s11431-014-5619-9.

[45] Naranjo-Pérez, J., Infantes, M., Fernando Jiménez-Alonso, J., Sáez, A. (2020). A collaborative machine learningoptimization algorithm to improve the finite element model updating of civil engineering structures, Engineering Structures, 225, https://doi.org/10.1016/j.engstruct.2020.111327.

[46] Bayes, M., Price, M. (1763). An essay towards solving a problem in the doctrine of chances, by the late rev. mr. bayes, frs communicated by mr. price., in a letter to john canton, amfrs.

[47] Jiménez-Alonso, J.F., Naranjo-Perez, J., Pavic, A., Sáez, A. (2020). Maximum Likelihood Finite-Element Model Updating of Civil Engineering Structures Using Nature-Inspired Computational Algorithms, Structural Engineering International, (1-13), https://doi.org/10.1080/10168664.2020.1768812.

[48] Olsson, D.M., Nelson, L.S. (1975). The nelder-mead simplex procedure for function minimization, Technometrics, 17, (45-51), https://doi.org/10.1080/00401706.1975.10489269.

[49] Jin, S.S., Jung, H.J. (2016). Sequential surrogate modeling for efficient finite element model updating, Computers and Structures, 168, (30-45), https://doi.org/10.1016/j.compstruc.2016.02.005.

[50] Levin, R.I., Lieven, N.A.J. (1998). Dynamic finite element model updating using simulated annealing and genetic algorithms, Mechanical Systems and Signal Processing, 12, (91-120), https://doi.org/10.1006/mssp.1996.0136.

[51] Kennedey, J., Eberhart, R. (1995). Particle Swarm Optimization, in: Proceedings of ICNN'95 - International Conference on Neural Networks, : pp. 1942-1948 https://doi.org/10.1002/9780470612163.

[52] Ren, W.-X., Fang, S.-E., Deng, M.-Y. (2011). Response Surface-Based Finite-Element-Model Updating Using Structural Static Responses, Journal of Engineering Mechanics, 137, (248-257), https://doi.org/10.1061/(asce)em.1943-7889.0000223.

[53] Hao, X., Liu, Y. (2011). Updating the finite element model of a bridge model using a hybrid optimization method, Key Engineering Materials, 456, (37-50), https://doi.org/10.4028/www.scientific.net/KEM.456.37.

[54] Jin, S.S., Cho, S., Jung, H.J., Lee, J.J., Yun, C.B. (2014). A new multi-objective approach to finite element model updating, Journal of Sound and Vibration, 333, (2323-2338), https://doi.org/10.1016/j.jsv.2014.01.015. 